\title{
First Synthesis of Continuous Mesoporous Copper Films with Uniformly Sized Pores by Electrochemical Soft Templating
}

\author{
Cuiling Li, Bo Jiang, Zhongli Wang, Yunqi Li, Md. Shahriar A. Hossain, Jung Ho Kim, \\ Toshiaki Takei, Joel Henzie, Ömer Dag, Yoshio Bando, and Yusuke Yamauchi*
}

\begin{abstract}
Although mesoporous metals have been synthesized by electrochemical methods, the possible compositions have been limited to noble metals (e.g., palladium, platinum, gold) and their alloys. Herein we describe the first fabrication of continuously mesoporous $\mathrm{Cu}$ films using polymeric micelles as soft templates to control the growth of $\mathrm{Cu}$ under sophisticated electrochemical conditions. Uniformly sized mesopores are evenly distributed over the entire film, and the pore walls are composed of highly crystalized $\mathrm{Cu}$.
\end{abstract}

$c$ reating extended metallic 3D architectures is important because such kind of well-patterned networks improves material utilization efficiency and catalytic activity ${ }^{[1]}$ The nanoscale structure of metals have been manipulated through various physical and synthetic routes. For example, top down nanofabrication can generate precisely defined structures down to the nanometer level, but making complex 3D structures is challenging. ${ }^{[2]}$ Likewise, free-standing metal nanoparticles can be assembled into large-scale superstructures, but the process tends to be rather slow. ${ }^{[3]}$ Especially, mesoporous metals have sparked great interest due to their large surface areas and uniformly-sized pores, opening up a wide range of applications. ${ }^{[4]}$ Growing metals in sacrificial templates has been extensively studied by developing new kinds of hard and soft templates that can guide the deposition of metals and then be removed to reveal the mesoporous metallic structures. ${ }^{[4 b, c, 5]}$ The lyotropic liquid crystal (LLC) method $^{[6]}$ has been designed to work in combination of electrochemical processes, and has been further extended for the synthesis of various mesoporous metals. To our knowledge, however, the compositions of mesoporous/nanoporous metals have been mostly limited in noble metals, such as $\mathrm{Pt},{ }^{[7]}$ $\mathrm{Au},{ }^{[8]} \mathrm{Pd},{ }^{[9]}$ and their mixtures, ${ }^{[10]}$ despite the diversity of the morphologies and the wide range of usage. To extend the

[*] Dr. C. Li, B. Jiang, Dr. Z. Wang, Y. Li, Prof. Dr. J. H. Kim, Dr. T. Takei, Dr. J. Henzie, Prof. Dr. Y. Bando, Prof. Dr. Y. Yamauchi

International Center for Materials Nanoarchitectonics (MANA)

National Institute for Materials Science (NIMS)

1-1 Namiki, Tsukuba, Ibaraki 305-0044 (Japan)

E-mail:Yamauchi.Yusuke@nims.go.jp

Dr. M. S. A. Hossain, Prof. Dr. J. H. Kim, Prof. Dr. Y. Yamauchi

Australian Institute for Innovative Materials (AIIM)

University of Wollongong

Squires Way, North Wollongong, NSW 2500 (Australia)

Prof. Dr. Ö. Dag

Department of Chemistry, Bilkent University

06800 Ankara (Turkey)

(2) Supporting information for this article can be found under: http://dx.doi.org/10.1002/anie.201606031. utility of the mesoporous materials and make them ubiquitous, we must focus on non-noble metals that are far more Earth abundant than noble metals. The preparation of porous non-noble metals, however, is still very challenging because of their low reduction potentials, high susceptibility upon exposure to solution and air, and uncontrollable deposition behaviors. $^{[11]}$

Copper $(\mathrm{Cu})$ is a good candidate for mesoporous synthesis because it is a relatively abundant metal and has been well known to exhibit size-dependent properties in various application fields (e.g., sensing, conductivity, anti-bacteria, selective conversion of $\mathrm{CO}_{2}$ into fuels). ${ }^{[12]}$ In particular, the high surface area and fast diffusion through the porous network makes these surfaces ideal for sensing applications. For example, a good non-enzymatic glucose-detection performance has been realized by using a $\mathrm{Cu}$-foam-based sensor because of the unimpeded mobility of glucose and its reaction products offered by the robust hierarchical porous architectures. ${ }^{[13]}$ Synthesis of such kind of $\mathrm{Cu}$ foams relied on evolved hydrogen bubbles as templates, exclusively resulting in micron-sized pores. ${ }^{[14]}$ We hypothesize that introducing uniformly spaced, nanometer-sized pores in $\mathrm{Cu}$ will greatly improve its sensing capability because of increased surface area and more uniform network for the diffusion of analytes. Nevertheless, it has been extremely difficult to create uniformly mesoporous $\mathrm{Cu}$ in part because $\mathrm{Cu}$ has a strong preference even at small length scales, favoring polyhedral particles and wires instead of extended networks. ${ }^{[12 a, 15]}$

Herein we describe the synthesis of continuously mesoporous $\mathrm{Cu}$ films using block copolymers as soft templates. An external reducing potential was applied to guide the growth of $\mathrm{Cu}$, ultimately forming a diaphanous slab of mesoporous $\mathrm{Cu}$ (Scheme 1). The pore walls of these films are highly crystalline throughout the film-from the bottom to the top surface. Finally, we show that these mesoporous $\mathrm{Cu}$ films can efficiently and selectively detect glucose, even in actual serum samples.

In a typical preparation, $10 \mathrm{mg}$ of polystyrene- $b$-poly(oxyethylene) $\left(\mathrm{PS}_{63000}-b-\mathrm{PEO}_{26000}\right.$, abbreviated as PS- $b$-PEO) was dissolved in $3 \mathrm{~mL}$ of tetrahydrofuran (THF) at $50^{\circ} \mathrm{C}$, then $1.5 \mathrm{~mL}$ of ethanol was added to the solution. After the solution was thoroughly mixed, $1 \mathrm{~mL}$ of aqueous $\mathrm{CuSO}_{4}$ $(80 \mathrm{~mm})$ was added, resulting in the formation of spherical micelles. To increase the ionic conductivity of the electrolyte, $2.5 \mathrm{~mL}$ of $\mathrm{H}_{2} \mathrm{SO}_{4}(500 \mathrm{~mm})$ was added slowly to this mixture. Gentle stirring for $5 \mathrm{~h}$ ensured that the dissolved $\mathrm{Cu}$ species were well incorporated in the exterior PEO region of the micelles, resulting in a transparent light-green colored 

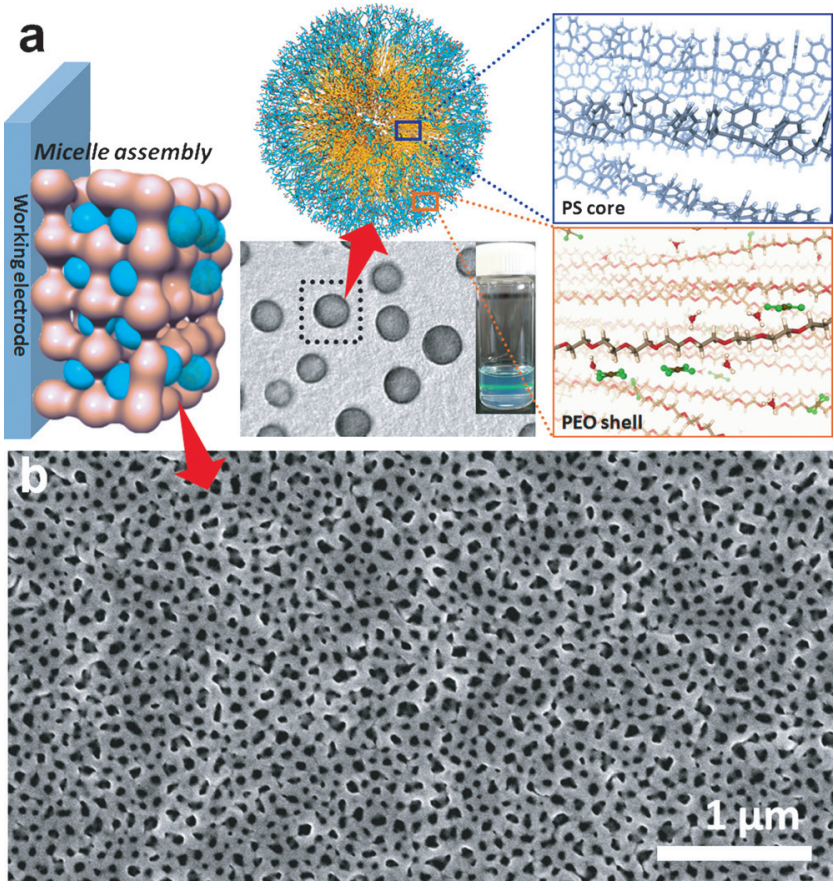

Scheme 1. a) Schematic illustration for the preparation process, and b) the typical SEM image of the mesoporous Cu film.

solution that was used for electrodeposition (see Supporting Information for additional details).

Using this solution as the electrolyte, the mesoporous $\mathrm{Cu}$ films were electrodeposited on a conductive Au-coated $\mathrm{Si}(\mathrm{Au}-\mathrm{Si})$ wafer at a constant voltage of $-0.4 \mathrm{~V}$ at room temperature and without stirring (see Supporting Information for additional details on the electrochemistry setup). The PS$b$-PEO was completely removed by ultraviolet ozone treatment. Scanning electron microscopy (SEM) micrographs show that the top side of the film is composed of uniformly distributed mesopores (Figure $1 \mathrm{a}, \mathrm{b}$ and Figure S1). The entire area of the film is homogenous and free of any defects such as perforations or bumps. According to SEM, the average pore size is about $48 \mathrm{~nm}$, with a wall thickness of approximately $65 \mathrm{~nm}$ (Figure $1 \mathrm{~b}$ and Figure S1). Longer deposition times led to thicker films. But surprisingly no variation in the size and uniformity of the pores regardless of thickness was observed. This approach shows a fairly high repeatability in the porous constructions no matter the variations of the electrolyte batches, making it a robust method for large-area mesoporous coating, perhaps extending to meter length scales (Figure S2).

A cross-sectional specimen sampled from the resulting mesoporous $\mathrm{Cu}$ film was further investigated by using transmission electron microscopy (TEM). Even in the earliest stages of deposition, the mesoporous structures formed on the $\mathrm{Au}-\mathrm{Si}$ substrate (Figure 1e and Figure S3a). High-resolution TEM (HRTEM) images show that the $\mathrm{Cu}$ frameworks are highly crystalline without any amorphous domains, and clear lattice fringes extended unabridged from bottom to top of the film (Figure $1 \mathrm{c}$ and Figure S3b-c). The lattice fringes with a constant $d$ spacing of $0.21 \mathrm{~nm}$ can be well ascribed to the (111) lattice planes of face-centered cubic (fcc) $\mathrm{Cu}$ crystals
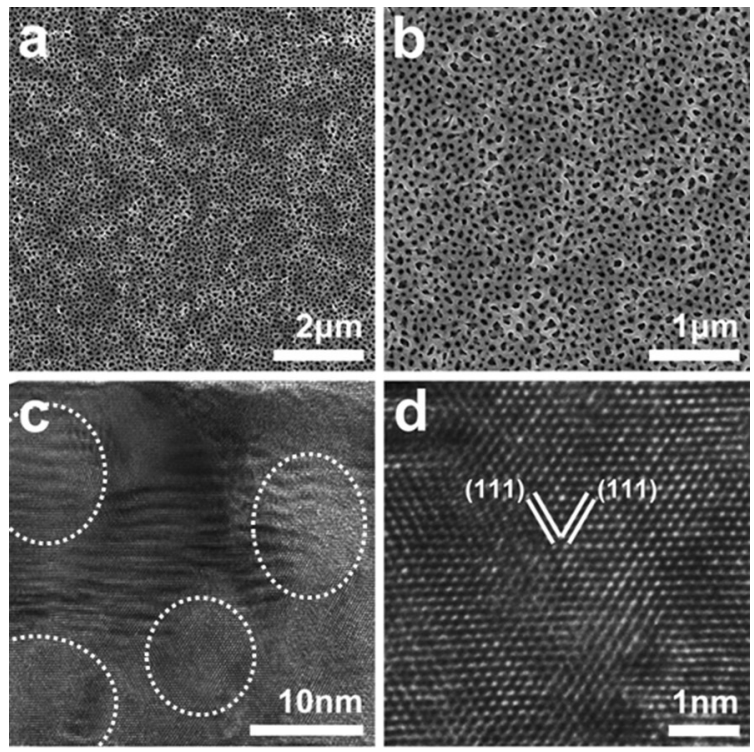

\section{e}

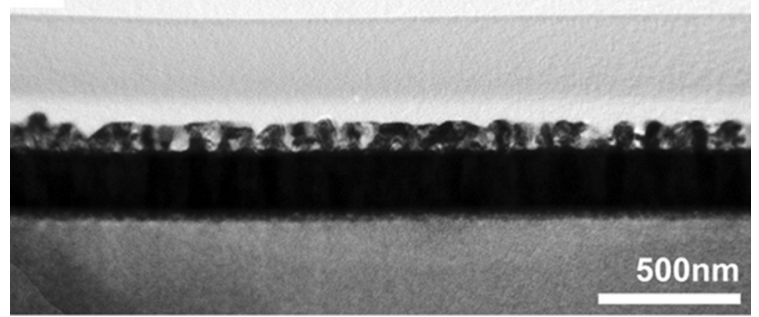

Figure 1. a),b) SEM images of the top-surface of the mesoporous $\mathrm{Cu}$ films. c),d) Cross-sectional HRTEM images of the mesoporous $\mathrm{Cu}$ films. The pores are indicated by circles in panel (c). e) Low-magnification TEM image of the cross-section of the mesoporous Cu film.

(Figure 1d). The crystallinity of the obtained $\mathrm{Cu}$ film was then studied by wide-angle X-ray diffraction (XRD) carried out in in-plane mode with various incident angles, which is sensitive to the lattice planes that are perpendicular to the film surface. With an incident angle in the range of $0.5-1.5^{\circ}$, the (220) diffraction peak ascribed to $\mathrm{Cu}$ fcc crystal is clearly observed, although a tiny intensity of other diffraction planes are observed (Figure S4). A deeper scanning to the $\mathrm{Cu}$ films at a higher incident angle $\left(>5.0^{\circ}\right)$ showed the diffraction peaks from the Au substrate. Thus, the in-plane XRD data shows the $\mathrm{Cu}$ crystals have a preferential orientation according to the (110) plane vertical to the substrate. In the case of onedimensional (1D) $\mathrm{Cu}$ nanowires, previous reports have demonstrated a crystal growth along the $\langle 110\rangle$ direction. ${ }^{[16]}$

The polymeric micelles play the central role in the fabrication of uniform mesoporous $\mathrm{Cu}$ films. Therefore, an investigation to the micellization process was conducted. In pure THF, the diblock copolymer, PS- $b$-PEO, is completely dissolved to be a clear solution without any micelles or aggregates (Figure $2 \mathrm{a}-\mathrm{i}$ ). The addition of ethanol and aqueous solution $\left(\mathrm{CuSO}_{4}\right.$ and $\left.\mathrm{H}_{2} \mathrm{SO}_{4}\right)$ led to a cloudy solution indicating the polymeric micelles, which was further evidenced by the Tyndall effect in the electrolyte (Figure $2 \mathrm{a}$-ii). It should be noted that the addition of $\mathrm{CuSO}_{4}$, caused the 

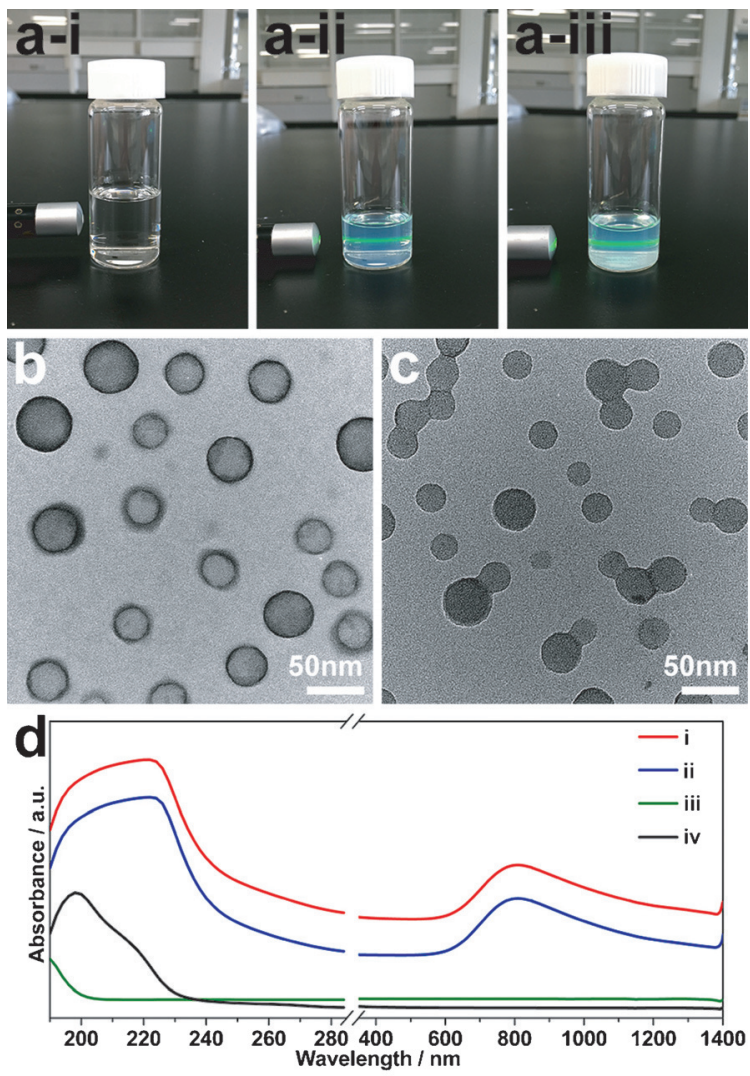

Figure 2. a) Optical micrographs demonstrating the emergence of the Tyndall effect in the electrolyte solution with different compositions: ai) PS-b-PEO dissolved in THF, a-ii) PS- $b$-PEO $+\mathrm{CuSO}_{4}+\mathrm{H}_{2} \mathrm{SO}_{4}$, and aiii) PS- $b$ - $\mathrm{PEO}+\mathrm{CuSO}_{4}$. Typical TEM images of the polymeric micelles b) before and c) after the addition of $\mathrm{CuSO}_{4}$ precursor. The samples are stained with $1.0 \mathrm{wt} \%$ phosphotungstic acid to highlight the micelles. d) UV/Vis-NIR spectra of different solutions: i) PS- $b$-PEO micelles $+\mathrm{CuSO}_{4}+\mathrm{H}_{2} \mathrm{SO}_{4}$, ii) $\mathrm{CuSO}_{4}$, iii) $\mathrm{H}_{2} \mathrm{SO}_{4}$, and iv) PS- $b$-PEO micelles, respectively. (Note: to highlight the interactions among different compositions, UV/Vis-NIR spectra of low- and high- wavelengths were obtained at different composition concentrations: low concentration for low-wavelength, and high concentration for highwavelength.)

micelles to aggregate slightly (Figure 2 b,c and Figure S5) and decrease in diameter (from $36 \mathrm{~nm}$ to $28 \mathrm{~nm}$; Figure S5). These observations indicate that the $\mathrm{CuSO}_{4}$ stimulated the interaction between the micelles. ${ }^{[5]}$

Retaining the micelle structure during $\mathrm{Cu}$ deposition, which depends on the interaction between the micelles and the metal precursors, was vital to the templating of uniform mesopores. To understand the formation mechanism of mesoporous $\mathrm{Cu}$, ultraviolet-visible-near infrared (UV/VisNIR) absorption measurements were carried out for the electrolyte solutions under our working conditions (Figure $2 \mathrm{~d}) . \mathrm{Cu}^{2+}$ ions are readily complexed with water and the peak at around $800 \mathrm{~nm}$ corresponds to a d-d transition of $\left[\mathrm{Cu}\left(\mathrm{H}_{2} \mathrm{O}\right)_{6}\right]^{2+}$ ion (Figure $2 \mathrm{~d}$ ). ${ }^{[17]}$ The other bands in the UV region of the spectrum originate from various moieties of the surfactants, such as the benzene rings of the phenyl group of the surfactant. $\mathrm{Cu}^{2+}$ ions in an octahedral field display a single $\mathrm{d}-\mathrm{d}$ transition from a ${ }^{2} \mathrm{E}_{\mathrm{g}}$ ground state to $\mathrm{a}^{2} \mathrm{~T}_{2 \mathrm{~g}}$ excited state. ${ }^{[17]}$ The tail on the low energy site is due to Jahn-Teller distortion. ${ }^{[17]}$ Although it is difficult to predict whether the coordination sphere is water molecule interacting with the ethylene oxide moiety of the micelles through hydrogen bonding or surfactant oxygen of the ethylene oxide units, the dissolved $\mathrm{Cu}$ species should be $2^{+}$charged. The $\mathrm{d}-\mathrm{d}$ band completely disappears upon electrochemical reduction process.

In the micelle solution, it is likely that the $\mathrm{CuSO}_{4}$ dissolved as $\left[\mathrm{Cu}\left(\mathrm{H}_{2} \mathrm{O}\right)_{6}\right]^{2+}$ and $\mathrm{SO}_{4}{ }^{2-}$ ions and interact with the ethylene oxide shell domains of the micelles. ${ }^{[18]} \mathrm{We}$ consider that the $\mathrm{Cu}$ ions can be, in the solution, as free ions as well as in the hydrophilic domains of the micelles. The micelles with $\mathrm{Cu}$ species could be neutral, negatively or positively charged depending on the $\mathrm{Cu}^{2+} / \mathrm{SO}_{4}{ }^{2-}$ ratios in the micelles. Since reduction takes place at the cathode, the $\mathrm{Cu}^{2+}$ rich micelles (overall positively charged ones) and free $\left[\mathrm{Cu}\left(\mathrm{H}_{2} \mathrm{O}\right)_{6}\right]^{2+}$ ions can be selectively directed to the cathode surface, where the $\mathrm{Cu}^{2+}$ ions are reduced to the metallic copper. The above formation mechanism satisfactorily explains the formation of mesopores in our self-assemblyreduction process.

The following chemical equilibrium [Eq. (1)] summarizes the assembly process, where " $M$ " stands for micelle, (aq) species are free ions, and $(n-m)$ can be negative or positive depending on the $\mathrm{Cu}^{2+} / \mathrm{SO}_{4}{ }^{2-}$ ratios.

$\mathrm{CuSO}_{4}+\mathrm{PS}-b$-PEO $+\mathrm{H}_{2} \mathrm{O} \rightarrow$

$\left[\mathrm{Cu}\left(\mathrm{H}_{2} \mathrm{O}\right)_{6}\right]^{2+}{ }_{(\mathrm{aq})}+\mathrm{SO}_{4}{ }^{2-}{ }_{\text {(aq) }}+\left[\mathrm{M}\left(\left[\mathrm{Cu}\left(\mathrm{H}_{2} \mathrm{O}\right)_{6}\right]^{2+}\right)_{n}\left(\mathrm{SO}_{4}{ }^{2-}\right)_{m}\right]^{2(n-m)+}$

The addition of $\mathrm{H}_{2} \mathrm{SO}_{4}$ takes a substantial role in obtaining continuous mesoporous $\mathrm{Cu}$ films. In the absence of $\mathrm{H}_{2} \mathrm{SO}_{4}$, only isolated $\mathrm{Cu}$ nanoparticles are confirmed on the substrate (Figure S6). By gradual increase the concentration of $\mathrm{H}_{2} \mathrm{SO}_{4}$, the porous structures of the continuous $\mathrm{Cu}$ film become apparent. Further optimization of the technique led us to settle on a $\mathrm{H}_{2} \mathrm{SO}_{4}$ concentration of $156.25 \mathrm{~mm}$ (Figure S7). Our method is distinctly different from previous reports that use $\mathrm{H}_{2} \mathrm{SO}_{4}$ to create $\mathrm{H}_{2}$ bubbles that direct the formation of large-sized pores in the films. ${ }^{[14,19]}$ In our method, $\mathrm{H}_{2} \mathrm{SO}_{4}$ has two essential effects: 1) the addition of $\mathrm{H}_{2} \mathrm{SO}_{4}$ solution can prevent a formation of hydroxides of $\mathrm{Cu}$ precursors, ${ }^{[20]}$ which can be well supported by the transparent solution with $\mathrm{H}_{2} \mathrm{SO}_{4}$ solution (Figure $2 \mathrm{a}$-ii), while, in the absence of $\mathrm{H}_{2} \mathrm{SO}_{4}$, some precipitates are formed at the bottom of the electrolyte (Figure 2a-iii); and 2) $\mathrm{H}_{2} \mathrm{SO}_{4}$ increases the ionic conductivity of the electrolyte, favoring a high deposition rate of $\mathrm{Cu}$ and the formation of continuous films. When the used acids were changed to other types, the quality of mesoporous structures was decreased (Figure $\mathrm{S} 8$ ).

The impact of $\mathrm{H}_{2} \mathrm{SO}_{4}$ on ionic conductivity can be observed in the electrodeposition traces before and after addition of acid (Figure S9a). Without $\mathrm{H}_{2} \mathrm{SO}_{4}$, the cyclic voltammetric $(\mathrm{CV})$ curves show a very small and linear current response, suggesting the huge resistance of the electrolyte. Upon addition of $\mathrm{H}_{2} \mathrm{SO}_{4}$ solution, the $\mathrm{CV}$ curve showed two reduction processes that correspond to: $\mathrm{Cu}^{2+} \rightarrow$ $\mathrm{Cu}^{+}$and $\mathrm{Cu}^{+} \rightarrow \mathrm{Cu}^{0}$ (Figure S9a). According to the Pourbaix diagram, direct reduction of $\mathrm{Cu}^{2+}$ to $\mathrm{Cu}^{0}$ is possible by 
manipulating the reduction potential at such an acidic condition in the present study. ${ }^{[21]}$ This excludes the possibility for the formation of other $\mathrm{Cu}$ phases (e.g., $\mathrm{Cu}_{2} \mathrm{O}$ ). Additionally, the charge transfer resistance was further investigated at two different electrolytes. Without any doubt, the charge transfer resistance decreases dramatically upon the addition of $\mathrm{H}_{2} \mathrm{SO}_{4}$ (Figure S9b,c). We believe that this is the key to preparing continuous $\mathrm{Cu}$ films with high reproducibility.

The reduction rate of $\mathrm{Cu}$ species is also extremely important for the final mesoporous structures. ${ }^{[6 a, 8 a, 22]}$ Electrochemical deposition enables the precise regulation of the crystal growth manner of the $\mathrm{Cu}$ walls that form around the micelles. Variations in the structure of the mesopores could be observed by using different constant potentials between $-300 \mathrm{mV}$ and $-700 \mathrm{mV}$ (Figure S10). From the top surface structures of the obtained films, it is obvious that the mesoporous structures are greatly changed, and optimized at particular potentials (i.e., $-300 \mathrm{mV}$ and $-400 \mathrm{mV}$ ). A high reduction rate of $\mathrm{Cu}$ at relatively low potentials (e.g., $-600 \mathrm{mV}$ and $-700 \mathrm{mV}$ in the present work), affords extremely large sized $\mathrm{Cu}$ crystals at the initial stage, which then grow rapidly to exceed the size of the hydrophilic volume of the micelles, thus leading to films with inadequate porous structures (Figure S10d,e). ${ }^{[6 a, 9 b]}$

The films with good mesoporous structures, that were prepared at three different potentials (i.e., $-300 \mathrm{mV}$, $-400 \mathrm{mV}$ and $-500 \mathrm{mV}$ ), were studied by cyclic voltammetry to sign light on how the accessible surface area depends on the applied constant potentials. The mesoporous $\mathrm{Cu}$ film prepared at $-400 \mathrm{mV}$ had the highest current density compared to other films (Figure S11), indicating that the great advantage of perfect mesoporous structures. A high deposition potential $(-300 \mathrm{mV})$ resulted in a relatively slow reduction speed, and small nanocrystals are obtained on the surface of the films, as shown in the inset of Figure S11a. The formation of small nanocrystals caused by the slow deposition rate finally decreased the surface area of the porous film.

Non-enzymatic glucose sensors based on nanostructured $\mathrm{Cu}$ have been intensively studied owing to the material's good conductivity, low cost, and superior performance. As a result of its self-supported mesoporous structures, mesoporous $\mathrm{Cu}$ film is a good candidate for the direct detection of glucose to satisfy the requirements of diverse applications by maximizing the sensitivity and achieving favorable selectivity. A highly improved activity and selectivity toward the glucose detection was realized by using the nanoporous $\mathrm{Cu}$ film, indicating an attractive application for the daily use. The details are given in Figure S12 and Table S1.

In summary, we have, for the first time, demonstrated the preparation of large-scale mesoporous $\mathrm{Cu}$ films based on a novel and simple approach to precisely balance the growth manner of the $\mathrm{Cu}$ frameworks and the micelle structures regardless the substrate variations. The present success not only indicates the capability of creating mesoporous structures with highly crystalized metals, but also paves a new way for preparation of porous Earth-abundant metals for diverse applications and at low cost.

\section{Acknowledgments}

This work was partially supported by the Australian Institute for Innovative Materials (AIIM) Gold/2015 grant and the University of Wollongong's Global Challenge Program/2015 grant.

Keywords: copper - electrochemical deposition . mesoporous materials $\cdot$ micelles $\cdot$ soft-templates

How to cite: Angew. Chem. Int. Ed. 2016, 55, 12746-12750 Angew. Chem. 2016, 128, 12938-12942

[1] a) H. Zhang, X. Yu, P. V. Braun, Nat. Nanotechnol. 2011, 6, 277; b) C. V. Falub, H. von Känel, F. Isa, R. Bergamaschini, A. Marzegalli, D. Chrastina, G. Isella, E. Müller, P. Niedermann, L. Miglio, Science 2012, 335, 1330; c) X.-J. Wu, J. Chen, C. Tan, Y. Zhu, Y. Han, H. Zhang, Nat. Chem. 2016, 8, 470; d) B. Kong, J. Tang, Y. Zhang, T. Jiang, X. Gong, C. Peng, J. Wei, J. Yang, Y. Wang, X. Wang, G. Zheng, C. Selomulya, D. Zhao, Nat. Chem. 2016, 8,171 .

[2] a) K. Dietrich, D. Lehr, C. Helgert, A. Tünnermann, E.-B. Kley, Adv. Mater. 2012, 24, OP321; b) M. H. Lee, H. Gao, J. Henzie, T. W. Odom, Small 2007, 3, 2029; c) A. R. Halpern, R. M. Corn, ACS Nano 2013, 7, 1755.

[3] a) J. Henzie, M. Grünwald, A. Widmer-Cooper, P. L. Geissler, P. Yang, Nat. Mater. 2012, 11, 131; b) Y. H. Lee, W. Shi, H. K. Lee, R. Jiang, I. Y. Phang, Y. Cui, L. Isa, Y. Yang, J. Wang, S. Li, X. Y. Ling, Nat. Commun. 2015, 6, 6990; c) X. A. Zhang, B. Dai, Z. $\mathrm{Xu}$, C.-H. Chang, Small 2015, 11, 1285.

[4] a) V. Malgras, H. Ataee-Esfahani, H. Wang, B. Jiang, C. Li, K. C.-W. Wu, J. H. Kim, Y. Yamauchi, Adv. Mater. 2016, 28, 993; b) S. C. Warren, L. C. Messina, L. S. Slaughter, M. Kamperman, Q. Zhou, S. M. Gruner, F. J. DiSalvo, U. Wiesner, Science 2008, 320, 1748; c) H. Wang, H. Y. Jeong, M. Imura, L. Wang, L. Radhakrishnan, N. Fujita, T. Castle, O. Terasaki, Y. Yamauchi, J. Am. Chem. Soc. 2011, 133, 14526; d) K.-S. Choi, E. W. McFarland, G. D. Stucky, Adv. Mater. 2003, 15, 2018; e) V. Malgras, Q. Ji, Y. Kamachi, T. Mori, F. K. Shieh, K. C.-W. Wu, K. Ariga, Y. Yamauchi, Bull. Chem. Soc. Jpn. 2015, 88, 1171.

[5] a) Y. Yamauchi, K. Kuroda, Chem. Asian J. 2008, 3, 664; b) H. Wang, L. Wang, T. Sato, Y. Sakamoto, S. Tominaka, K. Miyasaka, N. Miyamoto, Y. Nemoto, O. Terasaki, Y. Yamauchi, Chem. Mater. 2012, 24, 1591; c) H. J. Shin, R. Ryoo, Z. Liu, O. Terasaki, J. Am. Chem. Soc. 2001, 123, 1246.

[6] a) G. S. Attard, C. G. Göltner, J. M. Corker, S. Henke, R. H. Templer, Angew. Chem. Int. Ed. Engl. 1997, 36, 1315; Angew. Chem. 1997, 109, 1372; b) G. S. Attard, P. N. Bartlett, N. R. B. Coleman, J. M. Elliott, J. R. Owen, J. H. Wang, Science 1997, 278, 838.

[7] a) B. Jiang, C. Li, V. Malgras, M. Imura, S. Tominaka, Y. Yamauchi, Chem. Sci. 2016, 7, 1575; b) C. Li, T. Sato, Y. Yamauchi, Angew. Chem. Int. Ed. 2013, 52, 8050; Angew. Chem. 2013, 125, 8208; c) Y. Li, B. P. Bastakoti, V. Malgras, C. Li, J. Tang, J. H. Kim, Y. Yamauchi, Angew. Chem. Int. Ed. 2015, 54, 11073; Angew. Chem. 2015, 127, 11225; d) X. Teng, X. Liang, S. Maksimuk, H. Yang, Small 2006, 2, 249.

[8] a) C. Li, Ö. Dag, T. D. Dao, T. Nagao, Y. Sakamoto, T. Kimura, O. Terasaki, Y. Yamauchi, Nat. Commun. 2015, 6, 6608; b) S. Pedireddy, H. K. Lee, W. W. Tjiu, I. Y. Phang, H. R. Tan, S. Q. Chua, C. Troadec, X. Y. Ling, Nat. Commun. 2014, 5, 4947; c) M. K. Khristosov, L. Bloch, M. Burghammer, Y. Kauffmann, A. Katsman, B. Pokroy, Nat. Commun. 2015, 6, 8841 .

[9] a) X. Huang, Y. Li, Y. Chen, E. Zhou, Y. Xu, H. Zhou, X. Duan, Y. Huang, Angew. Chem. Int. Ed. 2013, 52, 2520; Angew. Chem. 2013, 125, 2580; b) C. Li, B. Jiang, N. Miyamoto, J. H. Kim, V. 
Malgras, Y. Yamauchi, J. Am. Chem. Soc. 2015, 137, 11558; c) C. Li, T. Sato, Y. Yamauchi, Chem. Commun. 2014, 50, 11753.

[10] a) B. Lim, M. Jiang, P. H. C. Camargo, E. C. Cho, J. Tao, X. Lu, Y. Zhu, Y. Xia, Science 2009, 324, 1302; b) B. Jiang, C. Li, M. Imura, J. Tang, Y. Yamauchi, Adv. Sci. 2015, 2, 1500112; c) H Ataee-Esfahani, M. Imura, Y. Yamauchi, Angew. Chem. Int. Ed. 2013, 52, 13611; Angew. Chem. 2013, 125, 13856.

[11] M. Wang, L. Wang, H. Li, W. Du, M. U. Khan, S. Zhao, C. Ma, Z. Li, J. Zeng, J. Am. Chem. Soc. 2015, 137, 14027.

[12] a) D. Zhang, R. Wang, M. Wen, D. Weng, X. Cui, J. Sun, H. Li, Y. Lu, J. Am. Chem. Soc. 2012, 134, 14283; b) B. Thakur, E. Bernalte, J. P. Smith, C. W. Foster, P. E. Linton, S. N. Sawant, C. E. Banks, Analyst 2016, 141, 1233; c) H. Pang, Q. Lu, J. Wang, Y. Li, F. Gao, Chem. Commun. 2010, 46, 2010; d) C. W. Li, M. W. Kanan, J. Am. Chem. Soc. 2012, 134, 7231.

[13] X. Niu, Y. Li, J. Tang, Y. Hu, H. Zhao, M. Lan, Biosens. Bioelectron. 2014, 51, 22.

[14] a) H.-C. Shin, M. Liu, Chem. Mater. 2004, 16, 5460; b) Y. Li, W.Z. Jia, Y.-Y. Song, X.-H. Xia, Chem. Mater. 2007, 19, 5758; c) J.H. Kim, R.-H. Kim, H.-S. Kwon, Electrochem. Commun. 2008 $10,1148$.

[15] a) X. Huang, Y. Chen, C.-Y. Chiu, H. Zhang, Y. Xu, X. Duan, Y. Huang, Nanoscale 2013, 5, 6284; b) H. Guo, Y. Chen, H. Ping, J. Jin, D.-L. Peng, Nanoscale 2013, 5, 2394; c) G. Guisbiers, S. Mejia-Rosales, S. Khanal, F. Ruiz-Zepeda, R. L. Whetten, M. José-Yacaman, Nano Lett. 2014, 14, 6718.
[16] a) A. R. Rathmell, S. M. Bergin, Y.-L. Hua, Z.-Y. Li, B. J. Wiley, Adv. Mater. 2010, 22, 3558; b) J. Song, J. Li, J. Xu, H. Zeng, Nano Lett. 2014, 14, 6298; c) Y. Zhao, Y. Zhang, Y. Li, Z. Yan, New J. Chem. 2012, 36, 130.

[17] A. B. P. Lever, Inorganic Electronic Spectroscopy, Elsevier, New York, 1968.

[18] Ö. Çelik, Ö. Dag, Angew. Chem. Int. Ed. 2001, 40, 3800; Angew. Chem. 2001, 113, 3916.

[19] a) J. Liu, L. Cao, W. Huang, Z. Li, ACS Appl. Mater. Interfaces 2011, 3, 3552; b) J. Zhang, M. D. Baró, E. Pellicer, J. Sort, Nanoscale 2014, 6, 12490.

[20] R. van den Berg, C. F. Elkjaer, C. J. Gommes, I. Chorkendorff, J. Sehested, P. E. de Jongh, K. P. de Jong, S. Helveg, J. Am. Chem. Soc. 2016, 138, 3433.

[21] a) G. Recio, D. Gallach, M. M. Silván, K. Fukami, R. J. M. Palma, G. R. Castro, Á. Muñoz-Noval, J. Phys. Chem. C 2014, 118, 14905; b) A. Cuenca, J. Agrisuelas, J. J. García-Jareño, F. Vicente, Langmuir 2015, 31, 12664.

[22] D. Grosso, C. Biossière, B. Smarsly, T. Brezesinski, N. Pinna, P. A. Albouy, H. Amenitsch, M. Antonietti, C. Sanchez, Nat. Mater. 2004, 3, 787.

Received: June 21, 2016

Published online: August 24, 2016 